\title{
Marina VIDAS, The Christina Psalter. A Study of the Images and Texts in a French Early Thirteenth-Century Illuminated Manuscript,
} Copenhague, Museum Tusculanum Press/University of Copenhagen Press, 2006, 154 pages, 20 planches, 21 figures.

Jean-Claude SCHMITT

\section{(2) OpenEdition}

\section{Journals}

Édition électronique

URL : https://journals.openedition.org/clio/6893

DOI : $10.4000 /$ clio.6893

ISSN : 1777-5299

Éditeur

Belin

Édition imprimée

Date de publication : 1 novembre 2007

Pagination : 232-264

ISBN : 978-2-85816-940-5

ISSN : 1252-7017

Référence électronique

Jean-Claude SCHMITT, « Marina VIDAS, The Christina Psalter. A Study of the Images and Texts in a

French Early Thirteenth-Century Illuminated Manuscript, », Clio. Femmes, Genre, Histoire [En ligne], $26 \mid$ 2007, mis en ligne le 14 avril 2008, consulté le 24 avril 2022. URL : http://journals.openedition.org/ clio/6893 ; DOI : https://doi.org/10.4000/clio.6893

Ce document a été généré automatiquement le 24 avril 2022

Tous droits réservés 


\section{Marina VIDAS, The Christina Psalter. A Study of the Images and Texts in a French Early Thirteenth-Century Illuminated Manuscript,}

Copenhague, Museum Tusculanum Press/University of Copenhagen Press, 2006, 154 pages, 20 planches, 21 figures.

Jean-Claude SCHMITT

1 Le manuscrit GKS 1606, $4^{\circ}$ de la Bibliothèque Royale de Copenhague n'est pas un inconnu, il s'en faut même de beaucoup, puisqu'il a depuis longtemps été pris en compte par les spécialistes des manuscrits français du début du XIIIe siècle (tel au premier rang Robert Branner) et comparé pour son iconographie aux psautiers royaux les plus prestigieux (le psautier d'Ingeburge de Danemark du Musée Condé à Chantilly ou le psautier de Blanche de Castille de la Bibliothèque de l'Arsenal). L'auteur confirme son origine parisienne et sa datation au début des années trente du XIIIe siècle. L'intérêt principal de l'étude réside dans le fait que tout un livre est consacré à ce psautier, qui le méritait bien. L'auteur étudie de près sa composition et son iconographie, dont celle des douze pleines-pages initiales qui subsistent sur quinze à l'origine (elles précèdent selon l'usage le calendrier et représentent la vie, la passion et la résurrection du Christ) et celle des huit initiales ornées des psaumes 1, 26, 38, 52, 68, $80,97,109$ (suivant une division du psautier commune à l'époque). Toutes ces images font l'objet d'une reproduction exhaustive dans les planches en couleur. Les vingt-etune figures en noir et blanc sont pour leur part des reproductions de pages entières de plusieurs manuscrits de la Bible Moralisée - un tel nombre n'était sans doute pas nécessaire à la démonstration -, notamment du manuscrit partagé entre Tolède et la Pierpont Morgan Library de New York, qui est daté de ca 1230 et présente selon l'auteur un grand nombre de traits iconographiques communs avec son manuscrit.

2 Le manuscrit GKS 1606, $4^{\circ}$ est traditionnellement associé à Christina de Norvège (1234-1262), fille du roi Hakon IV ; en 1258, elle a épousé l'Infant Philippe de Castille et 
Léon, petit neveu de Blanche de Castille: sur le chemin de l'Espagne, elle dut faire escale dans le royaume de France et aurait pu recevoir à cette occasion, de Louis IX, le psautier en cadeau de mariage, comme cela était habituel pour les princesses lors de leurs noces. D'autres hypothèses sont avancées pour expliquer la présence du manuscrit entre les mains de cette princesse norvégienne (un don de son mari, un don de Louis IX à Hakon IV et de celui-ci à sa fille, etc.). En tout cas, l'origine française ne fait pas de doute, tant en raison du style qu'en ce qui concerne le contenu, en particulier les litanies des saints, provenant de Saint-Germain-des-Prés, et le calendrier (nombreux saints parisiens et français). Originellement n'y figuraient ni saint François (canonisé en 1228), ni saint Dominique (canonisé en 1234), ce qui donne une indication sur la date approximative du manuscrit. Le calendrier se vit ajouter aussi des saints cisterciens et bénédictins, quand le manuscrit fut rapporté en Norvège après la mort de la princesse et entra dans la bibliothèque du monastère féminin de Nonneseter, près d'Oslo. On trouve également dans le manuscrit un témoignage tardif et inattendu sur son usage: le texte, datable du XIVe-XVe siècle, d'une messe pour les femmes enceintes, destinée sans doute aux futures mères proches des nonnes et qui avaient recours aux services spirituels du monastère.

3 Ayant analysé comme il se doit les différentes parties du manuscrit (les pleines-pages, le calendrier, une table pascale, la division des 150 psaumes, les cantiques, les litanies), l'auteur entreprend de comparer ce manuscrit à d'autres manuscrits français et anglais contemporains et proches : le psautier d'Ingeburge, le psautier de Leyde, le psautier de Blanche de Castille, le psautier de Saint-Louis (BnF Lat. 10434) et surtout les quatre Bibles Moralisées du XIIIe siècle (Vienne 2554 et Vienne 1179, Tolède-New York, Oxford-Paris-Londres). On l'a dit, c'est le troisième de ces manuscrits, plutôt que le quatrième, qui semble surtout se prêter à la comparaison iconographique: la démonstration est effectivement convaincante. Tous les arguments (données du calendrier, des litanies, contexte historique, style de l'iconographie) font pencher vers une réalisation sous la régence de Blanche de Castille, entre 1226 et 1235.

Dans la conclusion, l'auteur veut aller plus loin et trouver dans les images une « antijewish imagery" qui permettrait de rapprocher mieux encore le manuscrit de la régence de Blanche, marquée en effet par un raidissement de la monarchie à l'égard des juifs (voir les travaux de William Chester Jordan) : on peut la suivre dans ce qu'elle dit de l'image des juifs qui viennent en groupe circonvenir Hérode (une iconographie effectivement rare), mais l'exemple des marchands chassés du temple est tout sauf convaincant, puisque ces marchands ne portent aucun signe distinctif des juifs (ni chapeau pointu, ni rouelle). L'assimilation aux juifs des marchands du temple est effectivement avérée dès le XIe siècle. Mais ce n'est pas le cas ici et il faudrait plutôt invoquer à propos de cette image la politique royale contre les usuriers.

Que cette iconographie exalte la royauté (notamment à travers les initiales historiées des psaumes, mais aussi dans les pleines-pages, par l'importance accordée aux rois mages), cela est indéniable. Dans l'initiale du psaume 1 (Beatus vir), David est à la fois couronné et oint, ce qui est rare et méritait en effet d'être souligné. L'auteur met ce détail important en rapport avec l'obligation, durant la régence, d'affirmer la légitimité du jeune Louis IX contre les prétentions du demi-frère de Louis VIII, Philippe Hurepel, mais je doute de la pertinence de cette interprétation, qui suppose un lien immédiat entre une intention politique et une inflexion de l'iconographie biblique, sans compter 
que la règle de succession en ligne directe n'avait aucune raison d'être remise en cause puisqu'il y avait un roi et que sa jeunesse ne diminuait en rien sa légitimité.

6 On peut discuter de tel ou tel point d'interprétation. Plus critiquable est la rapidité du commentaire, par exemple sur le texte même des prières (la question classique de savoir si le texte fait parler une peccatrix ou un peccator n'est pas même posée). De façon générale, le livre offre une présentation suffisante pour une première approche, mais non l'étude exhaustive qu'on pouvait attendre (il n'y a par exemple aucune étude codicologique, pas le moindre schéma des cahiers de parchemin, comme cela est l'usage, et l'examen paléographique se limite à un paragraphe de 14 lignes). Il reste que ce livre présente un bon exemple de manuscrit de prière destiné à une femme et qu'il contribue - avec les autres manuscrits "féminins" analogues qui ont été cités - à mieux faire comprendre la dévotion et la «culture visuelle » communes aux reines et aux princesses de l'Europe du début du XIIIe siècle, ce qui est bien l'essentiel. 